\title{
Unruptured aneurysm of the sinus of Valsalva: a potential source of cerebrovascular embolism
}

\author{
Rashid M Shahrabani, P S Jairaj
}

\begin{abstract}
An unruptured aneurysm of the right sinus of Valsalva with intraluminal thrombus that displaced the right coronary artery ostium was diagnosed in a $\mathbf{3 0}$ year old Omani man who was investigated for uncontrolled grand mal epilepsy and residual left hemiparesis caused by occlusion of the right middle cerebral artery. Surgical intra-aortic closure of the aneurysm, which necessitated a saphenous vein graft to the right coronary artery, was successful. An aneurysm of the sinus of Valsalva is an unusual cause of a thromboembolic cerebrovascular accident.
\end{abstract}

\section{(Br Heart f 1993;69:266-267)}

An unruptured congenital aneurysm of the sinus of Valsalva is usually caused by the absence of the media in the aortic wall behind the sinus of Valsalva. Such aneurysms usually enlarge over the years but remain asymptomatic and often present after their rupture. There have been reports of unruptured aneurysms with intraluminal thrombus. ${ }^{1} \mathrm{We}$ describe a young patient with a large unruptured aneurysm of the right sinus of Valsalva containing thrombus. He had a history of a cerebrovascular accident caused by an embolus to the right middle cerebral artery.

\section{Case report}

A 30 year old man with uncontrolled grand mal epileptic seizures was referred to the neu-

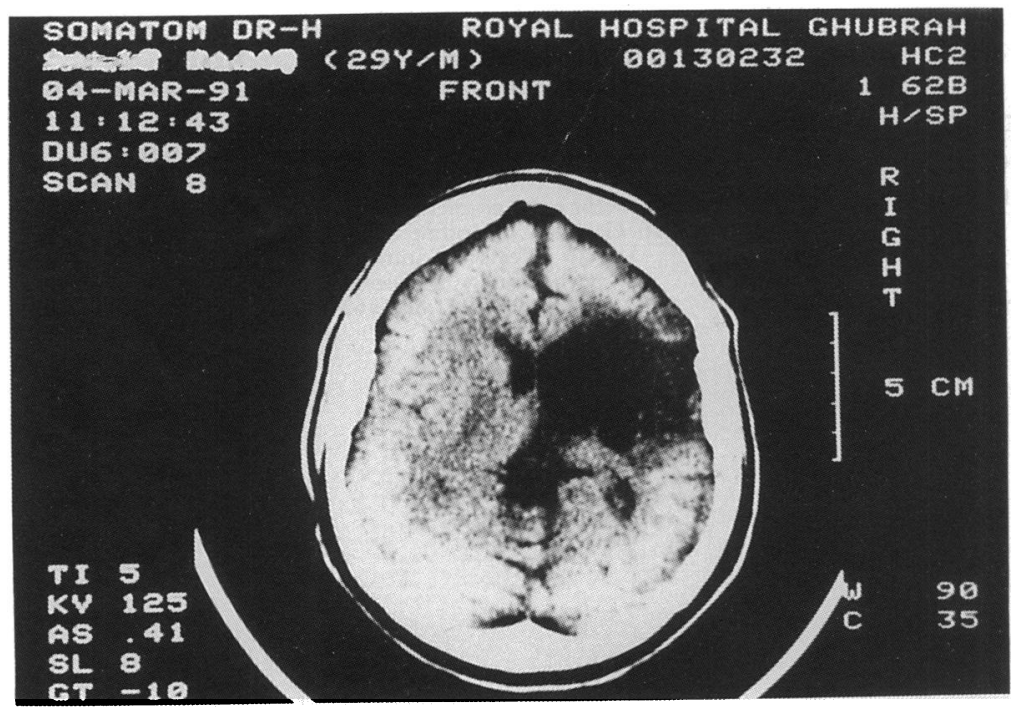

Figure 1 Computed tomography of the brain showing a large right cerebral infarction. rology department. The patient had sustained a cerebrovascular accident with left hemiplegia in 1984 from which he recovered almost fully. He underwent full investigations including cross sectional echocardiography, computed tomography, and carotid angiography which confirmed total occlusion of the right middle cerebral artery. There was an arteryrelated area of cerebral infarction (fig 1) and a small aneurysm of the right sinus of Valsalva. Examination during a recent admission showed a fully alert patient, in sinus rhythm, with a blood pressure of $110 / 70 \mathrm{~mm} \mathrm{Hg}$. There were dual heart sounds and no murmurs. The respiratory system was clear. Examination of the central nervous system showed mild left residual hemiparesis.

Electrocardiography showed sinus rhythm and the configuration was within normal limits. Biochemical and haematological variables, including the lipid profile, were within normal limits. The chest $x$ ray was normal except for the presence of a shadow with eggshell-like calcification within the cardiac silhouette. The shadow was related to the right ventricle. Cross sectional echocardiography confirmed the presence of an unruptured aneurysm of the right sinus of Valsalva.

Cardiac catheterisation confirmed the presence of an aneurysm of the right sinus of Valsalva with intraluminal thrombus. There was no evidence of aortic stenosis or regurgitation. Left and right ventricular haemody-

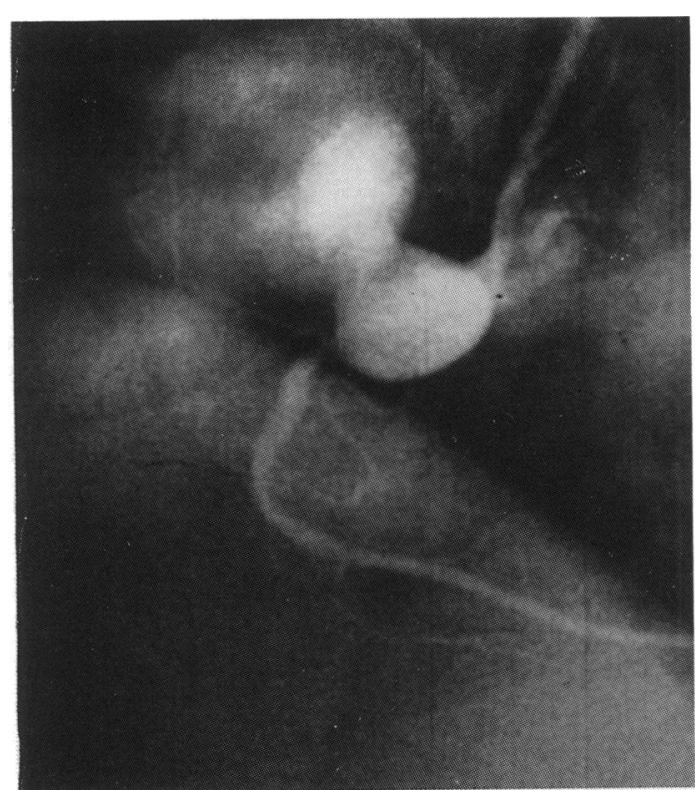

Figure 2 Right coronary sinus angiogram showing a large aneurysm of right sinus of Valsalva with eggshell-like calcification and a normal dominant right coronary artery. 
namic variables and function were normal. Selective coronary angiography showed a normal left coronary artery. The right coronary artery was dominant and healthy, but its ostium was appreciably displaced by the aneurysm (fig 2).

At operation there was an aneurysm $(5 \times 4$ $\mathrm{cm}$ ) arising from the right sinus of Valsalva. Its wall was calcified and adherent to the right ventricle. The aneurysm contained organised thrombus and the coronary artery ostium was displaced down below the neck of the aneurysm. The opening of the aneurysm was closed with Gore-Tex patch and because this effectively shut off the ostium of the right coronary artery, a saphenous vein bypass graft was implanted. The patient's recovery was uneventful.

\section{Discussion}

An unruptured congenital aneurysm of a sinus of Valsalva does not usually cause symptoms. Enlargement may occur and can present as a mediastinal mass, ${ }^{1}$ right ventricular outflow obstruction, ${ }^{2}$ coronary artery occlu- sion, ${ }^{3}$ ventricular tachycardia, ${ }^{4}$ and sudden cardiac death. ${ }^{5}$

We know of no other published reports that such an aneurysm can be a source of embolus owing to thrombus formation within its lumen. In this young man no other cause such as cerebrovascular atherosclerosis, carotid artery stenosis, cerebral arteriovenous malformation, or hyperlipidaemia accounted for the stroke. There was no intrinsic cardiac abnormality. We postulate that the aneurysm was the source of cerebral embolism and that subsequent organisation of the clot prevented further embolisation.

1 Reid PG, Goudevenos JA, Hilton CJ. Thrombosed saccular aneurysm of a sinus of Valsalva: unusual cause of a mediastinal mass. Br Heart f 1990;63:183-5.

2 Haraphongse $M$, Ayudha $R K$, Jugdutt $B$, Rossall $R$. Isolated unruptured sinus of Valsalva aneurysm producing right ventricular outflow obstruction. Cathet Cardiovasc Diagn 1990;19:98-102.

3 Chipdiovasc Diagn 1990;19:98-102. Valsalva causing coronary occlusion. Arch Pathol Lab Med 1941;31:627-30.

4 Channer KS, Hutter JA, George M. Unruptured aneurysm of sinus of valsalva presenting with ventricular tachycardia. Eur Heart $\mathcal{F}$ 1988;9:186-90.

5 Henry R, Daisley H, Barton E. Sudden cardiac death caused by coronary ostial compression by aneurysm of the sinus of Valsalva. West Indian Med F 1989;38:250-2. 